\title{
History of Atopy Confers Improved Outcomes In IDH Mutant And Wildtype Low-Grade Glioma
}

\author{
Emade Jaman ( $\square$ jamane@upmc.edu ) \\ University of Pittsburgh Medical Center https://orcid.org/0000-0002-7044-7196 \\ Xiaoran Zhang \\ University of Pittsburgh Medical Center \\ Poorva Sandlesh \\ UPMC Hillman Cancer Center \\ Ahmed Habib \\ UPMC Hillman Cancer Center \\ Jordan Allen \\ UPMC Hillman Cancer Center
}

Raj G. Saraiya

University of Pittsburgh Dietrich School of Arts and Sciences

Pascal O. Zinn

UPMC Hillman Cancer Center

\section{Research Article}

Keywords: atopy, allergy, IDH, low grade glioma, BDNF

Posted Date: August 18th, 2021

DOl: https://doi.org/10.21203/rs.3.rs-784423/v1

License: (c) (1) This work is licensed under a Creative Commons Attribution 4.0 International License.

Read Full License 


\section{Abstract}

\section{Purpose:}

A history of atopy or allergy has been shown to be protective against the development of glioma, however the effect of atopy on patient outcomes, especially in conjunction with the survival benefit associated with IDH mutation, has not yet been investigated, and is the focus of the study we present here.

\section{Methods:}

Low grade glioma (LGG) data from the TCGA was downloaded, along with IDH, TERT, 1p/19q and ATRX mutational status and genetic alterations. History of asthma, eczema, hay fever, animal, or food allergies, as documented in TCGA, was used to determine patient atopy status. Patients with missing variables were excluded from the study.

\section{Results:}

374 LGG studies were included. Patients with a history of atopy demonstrated longer overall survival (OS) compared to those without ( 145.3 vs. 81.5 months, $p=00.0195)$. IDH mutant patients with atopy had longer OS compared those without atopy ( 158.8 vs. 85 months, $p=0.035$ ). Multivariate cox regression analysis demonstrated that the effects of atopy on survival were independent of IDH and histological grade, $(p=0.002, H R 0.257,95 \% 0.109-0.604),(p=<0.001, H R 0.217,95 \% 0.107-0.444)$, and $(p=0.004, H R$ $2.72,95 \% 1.373-5.397)$, respectively. In terms of treatment outcomes, patients with atopy did not differ in treatment response compared to their counterpart. Pathway analysis demonstrated an upstream activation of the BDNF pathway ( $p=0.00027)$.

\section{Conclusion:}

A history of atopy confers a survival benefit in patients with diffuse low-grade glioma. Activation of the BDNF pathway may drive the observed differences.

\section{Introduction}

Gliomas are the most common primary central nervous system (CNS) malignancies in adults accounting for almost $77 \%$ of primary brain tumors [1]. They are typically diagnosed based on histopathology and clinical criteria and classified by WHO (World Health Organization) criteria grade I-IV, with Diffuse Lowgrade glioma classified as WHO grade II \& III, dependent on key molecular alterations [2, 3]. Diffuse lowgrade glioma patients have a better overall survival outcome ( $\sim-7$ years) compared to high-grade glioma (WHO grade IV), glioblastoma (GBM), patients (12-16 months) [4-7]. Greater than 70\% of diffuse LGGs harbor a mutation in isocitrate dehydrogenase (IDH), which has been associated a survival advantage to the patients [2, 8-11]. Although IDH mutant (IDHm) LGG patients have a better prognosis, the immune microenvironment of patients harboring the IDH mutation is vastly different compared to the IDH wildtype (IDHwt) form of the disease [9]. IDHm LGGs have reduced innate and adaptive immune 
response seen in the form of decreased NK cell activity, decreased tumor-infiltrating lymphocytes, and increased circulating myeloid-derived tumor suppressor cells [8-10]. Much research has been dedicated to reversing this phenomenon with immunotherapy to increase patient outcomes [12].

Given the importance of immune driven defense against cancer, there has been considerable interest in understanding the effects of a "hyperactive" immune system, such as that which is seen in patients with a history of allergy or atopy, and the likelihood of these patients to develop various cancers, including glioma [13-16]. Although the association between atopic conditions such as allergy, asthma, and eczema has been investigated across various malignancies, the findings have remained relatively inconsistent throughout. Atopic conditions have been shown to have protective effects such as a lower incidence rate, or improved clinical outcomes in certain malignancies such as low-grade glioma, colorectal cancer, childhood leukemia, and pancreatic cancer [15]. Yet in other cancers such as lung cancer and melanoma, the findings remain inconclusive, or simply demonstrate the opposite effect [15, 16]. While a history of atopy \& allergy has been associated with protective features in LGG, clinical outcomes related studies remain insufficient or incomplete. To our knowledge only one such study exists [17] however, given the vast heterogeneity of LGG, both phenotypic and genetic, the effect of atopy is not

yet understood in the context of the IDH1 or IDH2 mutation, which in itself is known to be associated with improved clinical outcomes such as survival, when compared to wildtype glioma $[9,10]$. In this study, we use data from The Cancer Genome Atlas (TCGA) to analyze outcomes in low-grade glioma patients in the context of IDH mutations and tumor grade status to determine whether a history of atopy has any true influence on patient outcomes.

\section{Methods}

\section{Patients and Data Collection}

Using the TCGAbiolinks R package, Low-Grade Glioma (LGG) data were downloaded from the Genomics Data Commons Data Portal along with clinical data pertaining to each patient. Mutational data for IDH1, IDH2, TERT, ATRX, 1p19q co-deletion, was downloaded from cBioPortal for Cancer Genomics for each patient. Clinical variables included patient demographics such as age, gender, race, days to death, days to last follow up, and a history of atopy defined as having a history of one of the following: Asthma, eczema, food allergy, animal allergy, hay fever, or mold/dust energy. Inclusion criteria included adult LGG patients for which TCGA reported data on IDH mutational status, and atopy variables were available. Patients with incomplete or unavailable key data points were excluded from the analysis (Fig. 1). Days to the last follow-up, and days to death for each patient were also collected, along with treatment outcomes for patients undergoing treatment. Outcomes were stratified by TCGA as "Complete Remission/Response", "Partial Remission/Response", "Progressive Disease”, and "Stable Disease".

\section{Survival, Multivariate, and Statistical Analysis}

Kaplan Meier survival curves were generated using Graphpad Prism for Macintosh, and the Log-Rank test was applied to determine statistical significance at a threshold of $P<0.05$. Univariate and multivariate 
Cox Regression analyses were performed using R packages Survminer and Survival with statistical significance again defined as $P<0.05$.

\section{Differential Gene Expression and Pathway Analysis}

Raw RNAseq expression count data was downloaded for the LGG study sample from the TCGA using the TCGAbiolinks package. Data normalization and differential gene expression analysis were performed using the DESeq2 package. Parameters for significance in expression changes were set to a fold change of $+/-1.5$, with a false discovery rate (q-value) of less than 0.05 . Genes that met the significance criteria were then included in the pathway analysis performed using Ingenuity Pathway Analysis (IPA) from QIAGEN Inc. Statistical significance for pathway analysis was set at $P<0.05$.

\section{Results}

514 diffuse LGG patients were accessed from the PanCancer Atlas study within the TCGA. After careful review, 374 studies with both clinical and mutational data, were included for further analysis. In our study cohort, patients harboring either a mutation in IDH1 or IDH2 (83.2\%, $n=311)$, were shown to have a significantly higher overall survival with median survival in the IDHm sample of 101.3 months, compared to 22.8 in the IDHwt group $(p<0.0001$, HR 0.22, 95\% 0.12-0.42) (Fig. 2A). When looking at all 374 patients, a history of allergy or atopy $(23.3 \%, n=87)$ was also associated with a significantly longer overall survival, with a median survival of 145.3 months in atopic patients, compared to 81.5 months in patients without a history of atopy ( $p=0.0195$, HR 0.40, 95\% 0.22-0.74) (Fig. 2B). In the context of IDHm patients only, patients with atopy demonstrated an additional survival benefit with a median survival of 158.8 months compared to 85 months ( $p=0.0335$, HR 0.34, 95\% 0.16-0.72) (Fig. 2C). A history of atopy was also associated with an increased median overall survival in the IDHwt patient cohort, 145.3 months vs. 21.7 months (with atopy vs. no atopy IDHwt; $p=0.2150$, HR 0.49, 95\% 0.18-1.39) (Fig. 2D).

Histological grade was also taken into consideration as a potential confounding factor and therefore was analyzed with survival curves. Approximately an even number of samples were either identified as WHO Grade II, or WHO Grade III ( $n=185 ; 49.5 \%$, and $n=189 ; 50.5 \%$, respectively). In concordance with the literature, a significantly higher median overall survival was demonstrated in patients with WHO Grade II vs. Grade III glioma, 127.5 months compared to 56.6 ( $p<0.0001$, HR 0.30, 95\% 0.20-0.46) (Fig. 3A). Furthermore, a history of atopy was again associated with longer median survival in each subdivision (Grade II, and Grade III). In patients with WHO Grade II glioma and a history of atopy, median survival was 158.8 months compared to 103.8, ( $p=0.0024$, HR 0.97, 95\% 0.31-3.0) (Fig. 3B) while in WHO Grade III patients with atopy the median survival was 145.3 months compared to 47.8 ( $p=0.0013, \mathrm{HR} 0.19,95 \%$ 0.10-0.34) (Fig. 3C). Females with and without atopy were observed to have better overall survival, however, this was not statistically significant, and unlikely to drive the differences in survival attributable to atopy (Fig. 4A \& B).

Additionally, both univariate and multivariate Cox regression analyses were conducted to elucidate the effect of atopy on survival independent of mutations that are known to either positively or negatively 
influence overall survival outcomes. Univariate analysis of the IDH, TERT, 1p19q co-deletion, and ATRX mutation status demonstrated survival benefits associated with IDH mutation and the 1p19q co-deletion. Only 2 patients in the study tested positive for TERT mutations, rendering it insignificant. In our study population, ATRX appeared to have no significant effect on survival. Univariate testing showed a statistically significant effect of a history of atopy on survival, while a higher WHO grade was associated with lower overall survival. Assessing these variables with a multivariate analysis demonstrated that a history of atopy conferred a survival benefit independent of IDH mutation, and also independent of the histological grade of the tumor. ATRX mutations and 1p19q co-deletion status were not observed to independently influence survival in the context of IDH, atopy, and histological grade. This data is summarized in Table 2.

Data regarding treatment and treatment related outcomes were available for $50.8 \%(n=190)$ patients in our study cohort. Outcomes were defined as patients having complete remission/response, partial remission/response, progressive disease, or stable disease. For those patients with available outcomes data, $21 \%$ of patients $(n=40)$ had a history of atopy. In the atopy cohort, $40 \%(n=16)$ of patients experienced complete remission/response, 22.5\% ( $n=9)$ experienced partial remission/response, $10 \%$ ( $n$ $=4)$ experienced progressive disease, and $27.5 \%(n=11)$ experienced stable disease. These outcomes were not significantly different compared to the without atopy group, of which $30.7 \%(n=46)$ patients demonstrated complete remission/response, $26 \%(n=39)$ experienced a partial response, $15.3 \%(n=23)$ demonstrated progressive disease, and $28 \%(n=42)$ of patients demonstrated stable disease (Table 3$)$.

Further, differential gene expression analysis of RNAseq data was performed on all IDHm patients with and without atopy, given the larger sample size. Results of the differential gene expression were introduced to the Ingenuity Pathway Analysis platform (IPA), where the top canonical pathways were identified (Fig. 5A). IPA results also illustrated a relative upstream activation of the brain-derived neurotrophic factor (BDNF) pathway in those patients with a positive history of atopy $(p=0.00027)$ (Fig. $5 B)$.

\section{Discussion}

The association between cancer and conditions of atopy and allergy such as eczema, allergy (environmental, or food), hay fever, and asthma have long been studied to determine whether there appears to be a consistent trend between those who harbor these conditions and the development of cancers. While the results have been inconsistent across some malignancies, the literature offers relatively strong support in the case of glioma, with multiple observational and meta-analysis studies demonstrating an inverse relationship between patients with atopic conditions and the development of glioma [18-28]. As many of these studies have been observational epidemiological studies in nature, the mechanism for decreased risk of glioma in patients with atopy has not yet been described or elucidated. Studies conducted by Wiemels et al. have looked at IgE levels in patients with a history of atopy/allergy, initially demonstrating lower IgE levels in glioma patients, however, follow up studies remained inconclusive as treatment with temozolomide was thought to influence IgE levels [23, 24]. 
Despite numerous studies demonstrating the negative correlation between atopy and glioma development, outcomes-related data remains insufficient [28-32]. Furthermore, while this correlation has garnered strong support in the literature, there are some studies that do not strongly support this finding [33]. However, to our knowledge, only one study looking at outcomes of glioma patients with atopy was done by Lehrer et al [17]. In this study, the authors demonstrate a survival advantage in patients with atopy, independent of TERT mutations, 1p19q co-deletion, and histological grade. While the study demonstrated a strong association between patients with a history of atopy and increased overall survival, we were curious as to whether the survival benefits seen in atopic patients may be explained by the increased survival benefit conferred by the IDH mutation, as IDH status was not a covariate in the published study. In our study, we first demonstrated a survival benefit in patients harboring IDH1/2 mutations as evidenced and supported by the literature. Second, we demonstrated that patients harboring an IDH1/2 mutation, and carrying a clinical history of atopy/allergy, had an even longer overall survival than IDHm patients with no atopy (Fig. 1C). Third, we identified that a history of atopy is associated with increased survival via some mechanism independent of other mutations and genetic variations such as IDH mutation, histological grade (WHO Grade II vs. III), 1p19q co-deletion, and ATRX mutational status.

To investigate key pathways that may play a role in driving these survival benefits in diffuse LGG patients with a history of glioma, we performed a differential gene expression and pathway analysis. We focused on only the IDHm population in our sample as the majority, 79\% $(n=296)$, of patients in our study cohort, had either the IDH1 or IDH2 mutation. Using IPA, our analysis of canonical pathways was largely nonspecific, highlighting activation of CAMP-mediated signaling, GNRH signaling, CREB signaling in neurons, amongst others. Interestingly however, our upstream regulator pathway analysis showed activation in the brain-derived neurotropic factor (BDNF) pathway. Increased expression of BDNF by eosinophils is found to be crucial for atopic diseases such as allergic asthma and dermatitis [34]. Interestingly, BDNF's expression is documented to have both oncogenic and tumor-suppressive properties depending on the form of BDNF and on the cancer type [35,36]. Multiple studies have elucidated the potential role of eosinophilia and BDNF pathway activation in gliomas, for example, clinical studies conducted in postoperative IL-2 treated patients found enhanced GBM patient survival to be associated with tissue eosinophilia $[12,37,38]$. Furthermore, studies conducted in melanoma and in glioma indicated that activation of hypothalamic BDNF augments T-cell cytotoxicity to confer an anti-cancer phenotype [36, 39]. However, to fully understand the importance of BDNF pathway and eosinophilia in both LGG and GBM patient survival warrants further investigations.

In our study using TCGA data, we encountered a few limitations and attempt to address these. One limitation encountered was the fact that there is no data on the extent of resection for LGG surgeries. This data would ideally be used as a covariate in our multivariate analysis as the extent of surgical resection has been demonstrated to be a predictor of clinical outcomes [40-43]. Another limitation encountered is the unavailable WHO Grade I data. While diffuse low-grade gliomas are classified often by the IDH mutation and 1p19q status, our results show that atopy confers a survival benefit independent of these molecular alterations. Including Grade I gliomas would have been an interesting addition to our sample size, and would have strengthened our results should they have remained unchanged. Lastly, TCGA does 
not have atopy/allergy data for the glioblastoma (WHO Grade IV) studies. This would have also been a valuable addition to our study as the pervious metanalyses examining the effects of atopy, allergy and glioma have focused on gliomas as a whole. Analyzing GBM specifically would have also helped to identify whether the BDNF pathway is similarly upregulated in GBM patients with atopy as we see in diffuse LGG patients with atopy.

\section{Conclusion}

Altogether our study demonstrates a survival benefit in patients harboring IDH1/2 mutations which is further improved by a history of atopy. Moreover, we suggest that a history of atopy confers an increased survival potentially via a mechanism such as the activation of the BDNF pathway. This pathway may be an independent determinant of improved outcomes in this patient cohort, in addition to other mutations and genetic variations in glioma such as IDH mutation, histological grade (WHO Grade II vs. III), 1p19q codeletion, and ATRX mutational status.

\section{Declarations}

Funding: Not applicable

Conflict of Interest: All authors certify that they have no affiliations with or involvement in any organization or entity with any financial interest in the subject matter or materials discussed in this manuscript.

Availability of Data \& Material: All data used is publicly available from the TCGA and cBioPortal.

Code Availability: Not applicable

Authors' contributions: EJ \& XZ conceived and designed the study. EJ collected the data and performed the analyses. EJ, XZ, PS, JA, RS wrote the manuscript. AH \& POZ provided critical revision and performed edits. POZ provided final approval.

Ethics Approval: Not applicable

Consent to Participate: Not applicable

Consent for Publication: All authors listed contributing to the manuscript give consent for publication.

\section{ACKNOWLEDGMENTS:}

EJ is funded by the Dean's Research Fellowship. Awarded by the Dean of School of Medicine at the University of Pittsburgh School of Medicine to aspiring Physician-Scientists.

$\mathrm{XZ}$ is funded by the Physician-Scientist Incubator Program. The University of Pittsburgh holds a Physician Scientist Institutional Award from the Burroughs Welcome Fund. 


\section{References}

1. Schwartzbaum JA, Fisher JL, Aldape KD, Wrensch M. Epidemiology and molecular pathology of glioma. Nat Clin Pract Neurol. 2006;2(9):494-503; quiz 1 p following 16.

2. Chen R, Smith-Cohn M, Cohen AL, Colman H. Glioma Subclassifications and Their Clinical Significance. Neurotherapeutics. 2017;14(2):284-97.

3. Tom MC, Cahill DP, Buckner JC, Dietrich J, Parsons MW, Yu JS. Management for Different Glioma Subtypes: Are All Low-Grade Gliomas Created Equal? American Society of Clinical Oncology Educational Book. 2019(39):133-45.

4. Claus EB, Walsh KM, Wiencke JK, Molinaro AM, Wiemels JL, Schildkraut JM, et al. Survival and lowgrade glioma: the emergence of genetic information. Neurosurg Focus. 2015;38(1):E6.

5. Thakkar JP, Dolecek TA, Horbinski C, Ostrom QT, Lightner DD, Barnholtz-Sloan JS, et al. Epidemiologic and molecular prognostic review of glioblastoma. Cancer Epidemiol Biomarkers Prev. 2014;23(10):198596.

6. Bauchet L. Epidemiology of Diffuse Low Grade Gliomas. In: Duffau H, editor. Diffuse Low-Grade Gliomas in Adults. Cham: Springer International Publishing; 2017. p. 13-53.

7. Koshy M, Villano JL, Dolecek TA, Howard A, Mahmood U, Chmura SJ, et al. Improved survival time trends for glioblastoma using the SEER 17 population-based registries. J Neurooncol. 2012;107(1):20712.

8. Kohanbash G, Carrera DA, Shrivastav S, Ahn BJ, Jahan N, Mazor T, et al. Isocitrate dehydrogenase mutations suppress STAT1 and CD8+ T cell accumulation in gliomas. J Clin Invest. 2017;127(4):1425-37.

9. Amankulor NM, Kim Y, Arora S, Kargl J, Szulzewsky F, Hanke M, et al. Mutant IDH1 regulates the tumorassociated immune system in gliomas. Genes Dev. 2017;31(8):774-86.

10. Zhang X, Rao A, Sette P, Deibert C, Pomerantz A, Kim WJ, et al. IDH mutant gliomas escape natural killer cell immune surveillance by downregulation of NKG2D ligand expression. Neuro Oncol. 2016;18(10):1402-12.

11. Han S, Liu Y, Cai SJ, Qian M, Ding J, Larion M, et al. IDH mutation in glioma: molecular mechanisms and potential therapeutic targets. Br J Cancer. 2020;122(11):1580-9.

12. Hayes RL, Arbit E, Odaimi M, Pannullo S, Scheff R, Kravchinskiy D, et al. Adoptive cellular immunotherapy for the treatment of malignant gliomas. Crit Rev Oncol Hematol. 2001;39(1-2):31-42.

13. VENA JE, BONA JR, BYERS TE, MIDDLETON E, JR., SWANSON MK, GRAHAM S. ALLERGY-RELATED DISEASES AND CANCER: AN INVERSE ASSOCIATION. American Journal of Epidemiology. 
1985;122(1):66-74.

14. Talbot-Smith A, Fritschi L, Divitini ML, Mallon DFJ, Knuiman MW. Allergy, Atopy, and Cancer: A Prospective Study of the 1981 Busselton Cohort. American Journal of Epidemiology. 2003;157(7):606-12.

15. Rittmeyer D, Lorentz A. Relationship between allergy and cancer: an overview. Int Arch Allergy Immunol. 2012;159(3):216-25.

16. Wang $\mathrm{H}$, Diepgen $\mathrm{TL}$. Is atopy a protective or a risk factor for cancer? A review of epidemiological studies. Allergy. 2005;60(9):1098-111.

17. Lehrer S, Rheinstein PH, Rosenzweig KE. Allergy may confer better survival on patients with gliomas. Clin Neurol Neurosurg. 2019;177:63-7.

18. Brenner AV, Linet MS, Fine HA, Shapiro WR, Selker RG, Black PM, et al. History of allergies and autoimmune diseases and risk of brain tumors in adults. Int J Cancer. 2002;99(2):252-9.

19. Il'yasova D, McCarthy B, Marcello J, Schildkraut JM, Moorman PG, Krishnamachari B, et al. Association between glioma and history of allergies, asthma, and eczema: a case-control study with three groups of controls. Cancer Epidemiol Biomarkers Prev. 2009;18(4):1232-8.

20. Scheurer ME, El-Zein R, Thompson PA, Aldape KD, Levin VA, Gilbert MR, et al. Long-term antiinflammatory and antihistamine medication use and adult glioma risk. Cancer Epidemiol Biomarkers Prev. 2008;17(5):1277-81.

21. Schoemaker MJ, Swerdlow AJ, Hepworth SJ, McKinney PA, van Tongeren M, Muir KR. History of allergies and risk of glioma in adults. Int J Cancer. 2006;119(9):2165-72.

22. Schwartzbaum J, Jonsson F, Ahlbom A, Preston-Martin S, Lönn S, Söderberg KC, et al. Cohort studies of association between self-reported allergic conditions, immune-related diagnoses and glioma and meningioma risk. Int J Cancer. 2003;106(3):423-8.

23. Wiemels JL, Wiencke JK, Kelsey KT, Moghadassi M, Rice T, Urayama KY, et al. Allergy-related polymorphisms influence glioma status and serum IgE levels. Cancer Epidemiol Biomarkers Prev. 2007;16(6):1229-35.

24. Wiemels JL, Wiencke JK, Patoka J, Moghadassi M, Chew T, McMillan A, et al. Reduced immunoglobulin E and allergy among adults with glioma compared with controls. Cancer Res. 2004;64(22):8468-73.

25. Wiemels JL, Wiencke JK, Sison JD, Miike R, McMillan A, Wrensch M. History of allergies among adults with glioma and controls. Int J Cancer. 2002;98(4):609-15. 
26. Wiemels JL, Wilson D, Patil C, Patoka J, McCoy L, Rice T, et al. IgE, allergy, and risk of glioma: update from the San Francisco Bay Area Adult Glioma Study in the temozolomide era. Int J Cancer. 2009;125(3):680-7.

27. Wigertz A, Lönn S, Schwartzbaum J, Hall P, Auvinen A, Christensen HC, et al. Allergic conditions and brain tumor risk. Am J Epidemiol. 2007;166(8):941-50.

28. Chen C, Xu T, Chen J, Zhou J, Yan Y, Lu Y, et al. Allergy and risk of glioma: a meta-analysis. Eur J Neurol. 2011;18(3):387-95.

29. Amirian ES, Zhou R, Wrensch MR, Olson SH, Scheurer ME, Il'yasova D, et al. Approaching a Scientific Consensus on the Association between Allergies and Glioma Risk: A Report from the Glioma International Case-Control Study. Cancer epidemiology, biomarkers \& prevention : a publication of the American Association for Cancer Research, cosponsored by the American Society of Preventive Oncology. 2016;25(2):282-90.

30. Linos E, Raine T, Alonso A, Michaud D. Atopy and risk of brain tumors: a meta-analysis. J Natl Cancer Inst. 2007;99(20):1544-50.

31. Zhao H, Cai W, Su S, Zhi D, Lu J, Liu S. Allergic conditions reduce the risk of glioma: a meta-analysis based on 128,936 subjects. Tumour Biol. 2014;35(4):3875-80.

32. Turner MC, Krewski D, Armstrong BK, Chetrit A, Giles GG, Hours M, et al. Allergy and brain tumors in the INTERPHONE study: pooled results from Australia, Canada, France, Israel, and New Zealand. Cancer Causes Control. 2013;24(5):949-60.

33. Disney-Hogg L, Cornish AJ, Sud A, Law PJ, Kinnersley B, Jacobs DI, et al. Impact of atopy on risk of glioma: a Mendelian randomisation study. BMC Med. 2018;16(1):42.

34. Raap U, Goltz C, Deneka N, Bruder M, Renz H, Kapp A, et al. Brain-derived neurotrophic factor is increased in atopic dermatitis and modulates eosinophil functions compared with that seen in nonatopic subjects. J Allergy Clin Immunol. 2005;115(6):1268-75.

35. Yang B, Qin J, Nie Y, Li Y, Chen Q. Brain-derived neurotrophic factor propeptide inhibits proliferation and induces apoptosis in C6 glioma cells. Neuroreport. 2017;28(12):726-30.

36. Radin DP, Patel P. BDNF: An Oncogene or Tumor Suppressor? Anticancer Res. 2017;37(8):3983-90.

37. Curran CS, Bertics PJ. Eosinophils in glioblastoma biology. J Neuroinflammation. 2012;9:11-.

38. Hayes RL, Koslow M, Hiesiger EM, Hymes KB, Hochster HS, Moore EJ, et al. Improved long term survival after intracavitary interleukin-2 and lymphokine-activated killer cells for adults with recurrent malignant glioma. Cancer. 1995;76(5):840-52. 
39. Xiao R, Bergin SM, Huang W, Slater AM, Liu X, Judd RT, et al. Environmental and Genetic Activation of Hypothalamic BDNF Modulates T-cell Immunity to Exert an Anticancer Phenotype. Cancer Immunol Res. 2016;4(6):488-97.

40. Smith JS, Chang EF, Lamborn KR, Chang SM, Prados MD, Cha S, et al. Role of Extent of Resection in the Long-Term Outcome of Low-Grade Hemispheric Gliomas. Journal of Clinical Oncology. 2008;26(8):1338-45.

41. Hardesty D, Sanai N. The Value of Glioma Extent of Resection in the Modern Neurosurgical Era. Frontiers in Neurology. 2012;3(140).

42. Patel SH, Bansal AG, Young EB, Batchala PP, Patrie JT, Lopes MB, et al. Extent of Surgical Resection in Lower-Grade Gliomas: Differential Impact Based on Molecular Subtype. American Journal of Neuroradiology. 2019;40(7):1149-55.

43. Brown TJ, Brennan MC, Li M, Church EW, Brandmeir NJ, Rakszawski KL, et al. Association of the Extent of Resection With Survival in Glioblastoma: A Systematic Review and Meta-analysis. JAMA Oncol. 2016;2(11):1460-9.

\section{Tables}


Table 1: Patient Demographics and Comparisons

\begin{tabular}{|c|c|c|c|}
\hline Parameters & $\mathrm{n}$ & $\%$ & $P$ value \\
\hline \multicolumn{4}{|l|}{ All Patients } \\
\hline Males & 217 & $58.00 \%$ & - \\
\hline Females & 157 & $42.00 \%$ & - \\
\hline Mean Age (Years) & 42.2 & & - \\
\hline Dead at Last Follow Up & 52 & $13.90 \%$ & - \\
\hline Average Follow Up (Months) & 20.3 & & - \\
\hline Patients With Atopy & 87 & $23.30 \%$ & - \\
\hline Males & 44 & $50.10 \%$ & 0.108 \\
\hline Females & 43 & $49.40 \%$ & - \\
\hline Mean Age (Years) & 41.1 & & 0.194 \\
\hline Pre-Op KPS >80 & 52 & $86.70 \%$ & 0.324 \\
\hline Race/Ethnicity & & & - \\
\hline Non-Hispanic White & 81 & $93.10 \%$ & 0.003 \\
\hline Black/African American & 3 & $3.45 \%$ & - \\
\hline Hispanic/Latino & 1 & $1.15 \%$ & - \\
\hline Asian & 0 & - & - \\
\hline American Indian & 0 & - & - \\
\hline Unknown & 2 & $2.30 \%$ & - \\
\hline \multicolumn{4}{|l|}{ Atopy Criteria Met } \\
\hline Asthma & 16 & $18.40 \%$ & - \\
\hline Allergy & 6 & $6.90 \%$ & - \\
\hline Eczema & 6 & $6.90 \%$ & - \\
\hline Hay Fever & 20 & $23.00 \%$ & - \\
\hline Dust Allergy & 2 & $2.30 \%$ & - \\
\hline Food Allergy & 14 & $16.10 \%$ & - \\
\hline Animal Allergy & 5 & $5.74 \%$ & - \\
\hline One or More & 18 & $20.70 \%$ & - \\
\hline
\end{tabular}




\begin{tabular}{llll} 
Patients Without Atopy & 287 & $76.70 \%$ & - \\
\hline Males & 173 & $60.30 \%$ & - \\
\hline Females & 114 & $39.70 \%$ & - \\
\hline Mean Age (Years) & 42.5 & & - \\
\hline Pre-Op KPS & 154 & $91.10 \%$ & - \\
\hline Race/Ethnicity & & & \\
\hline Non-Hispanic White & 228 & $79.40 \%$ & - \\
\hline Black/African American & 11 & $3.83 \%$ & - \\
\hline Hispanic/Latino & 25 & $8.71 \%$ & - \\
\hline Asian & 4 & $1.39 \%$ & - \\
\hline American Indian & 1 & $0.35 \%$ & - \\
\hline Unknown & 18 & $6.27 \%$ & -
\end{tabular}

Table 2: Multivariate Analysis of Prognostic Parameters

\begin{tabular}{|c|c|c|c|c|c|}
\hline \multirow[t]{2}{*}{ Parameters } & & \multicolumn{2}{|l|}{ Univariate } & \multicolumn{2}{|l|}{ Multivariate } \\
\hline & $N=374$ & $\mathrm{HR}(95 \% \mathrm{Cl})$ & $P$ value & $\mathrm{HR}(95 \% \mathrm{Cl})$ & $P$ value \\
\hline \multicolumn{6}{|l|}{ IDH Status } \\
\hline Mutation & $311(83.2 \%)$ & $0.163(0.088-0.302)$ & $<0.001$ & $0.217(0.107-0.444)$ & $<0.001$ \\
\hline \multicolumn{6}{|l|}{ TERT Status } \\
\hline Mutation & $2(0.5 \%)$ & Undefined & 1 & - & - \\
\hline \multicolumn{6}{|l|}{ 1p19q Status } \\
\hline Co-Deletion & $126(33.7 \%)$ & $0.467(0.227-0.958)$ & 0.038 & $0.585(0.271-1.262)$ & 0.172 \\
\hline \multicolumn{6}{|l|}{ ATRX Status } \\
\hline Mutation & $142(38.0 \%)$ & $0.873(0.502-1.516)$ & 0.629 & - & - \\
\hline \multicolumn{6}{|l|}{ Atopy Status } \\
\hline Positive History & $87(23.3 \%)$ & $0.398(0.179-0.886)$ & 0.024 & $0.257(0.109-0.604)$ & 0.002 \\
\hline \multicolumn{6}{|c|}{ Histological Grade } \\
\hline Grade II & $185(49.5 \%)$ & 3.571 (1.889-6.751) & $<0.001$ & $2.722(1.373-5.397)$ & 0.004 \\
\hline Grade III & 189 (50.5\%) & & & & \\
\hline
\end{tabular}


Table 3: Comparison of Treatment Response

\begin{tabular}{llll} 
Parameters & With Atopy $(\mathrm{n}=40)$ & Without Atopy $(\mathrm{n}=150)$ & P Value \\
\hline & $\mathrm{n}(\%)$ & & \\
\hline Complete Remission/Response & $16(40.0 \%)$ & $46(30.7 \%)$ & 0.263 \\
\hline Partial Remission/Response & $9(22.5 \%)$ & $39(26.0 \%)$ & 0.651 \\
\hline Progressive Disease & $4(10.0 \%)$ & $23(15.3 \%)$ & 0.391 \\
\hline Stable Disease & $11(27.5 \%)$ & $42(28.0 \%)$ & 0.95
\end{tabular}

\section{Figures}




\section{Diffuse Low-Grade Glioma Studies Identified in TCGA}

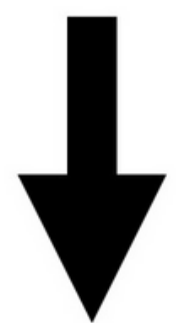

Studies Removed

139 Studies with unavailable atopy data

2 Studies with both unavailable IDH \& Atopy data

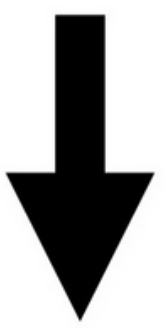

374 Diffuse Low-Grade Glioma Studies Included for Analysis

Figure 1

Flow Diagram of TCGA studies included in the final analysis. 


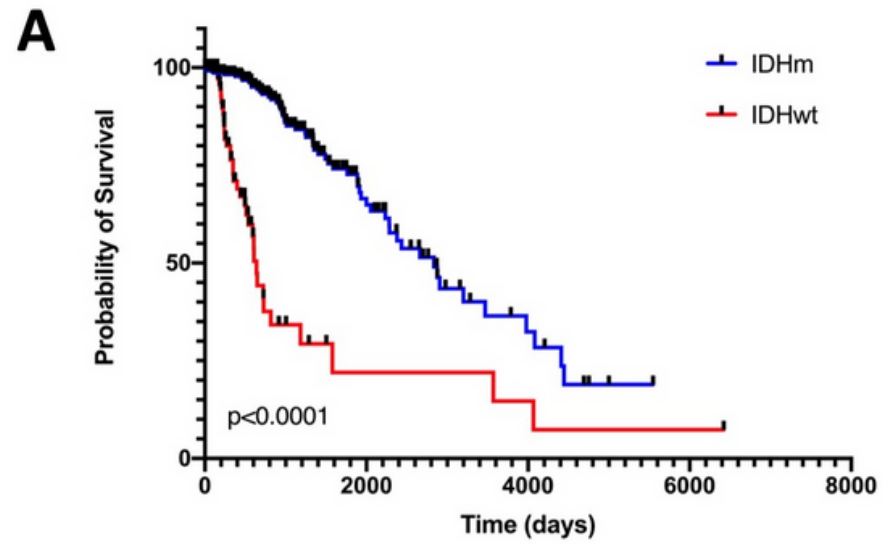

Atopy in IDHmut Patients
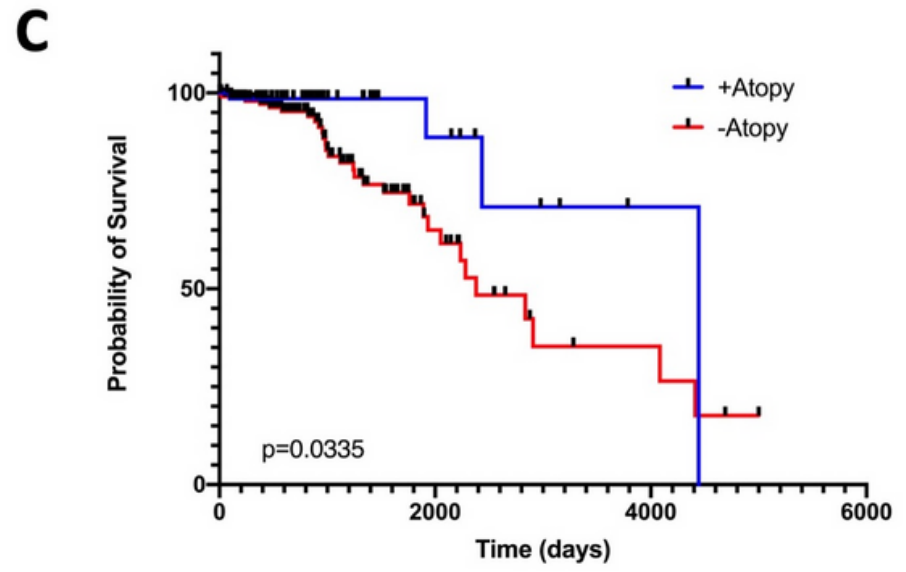

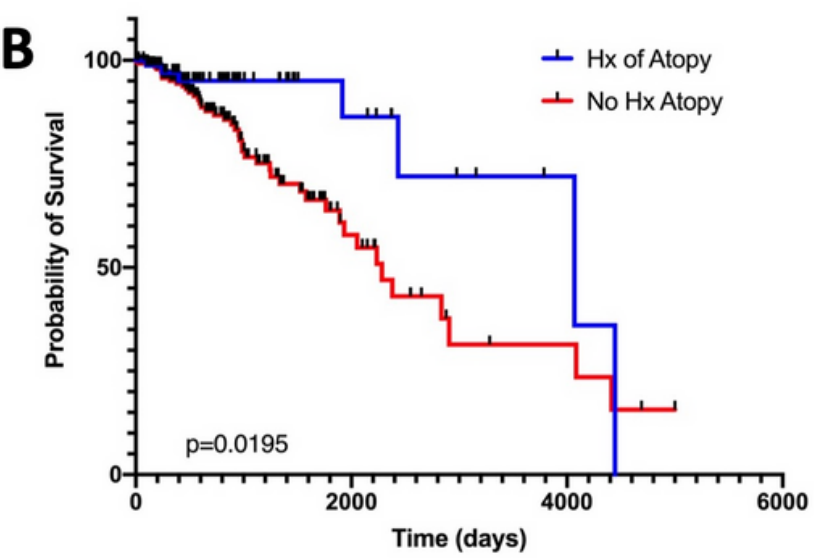

Atopy in IDHwt Patients

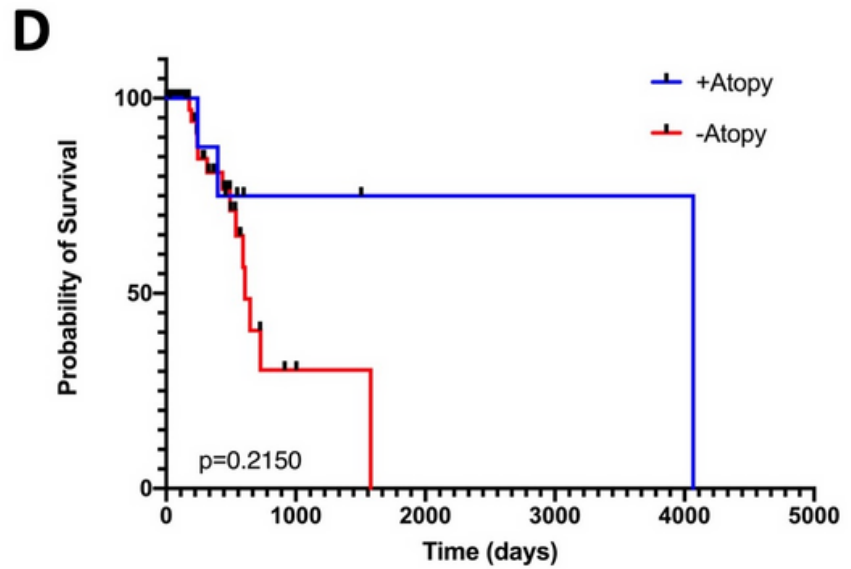

Figure 2

Kaplan Meier survival curves depicting overall survival of patients. A) Comparison of IDH Mutant LGG patients to IDH Wildtype demonstrated a statistically significant increased overall survival in the IDH mutant population. B) Comparison of patients with a history of atopy to those without demonstrared a significantly longer overall survival amongst patients with a history of atopy. C) Comparison of IDH mutant patients with atopy to IDH mutant patients without atopy showed statistically significant increase in overall survival in IDH mutant patients with atopy. D) Comparison of IDH wildtype patients with atopy to those without atopy demonstrating an increase in overall survival in IDH mutant patients that have a history of atopy, which was non-significant. 
A

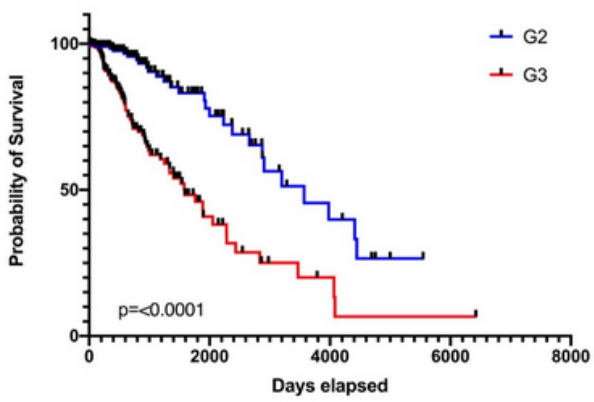

B

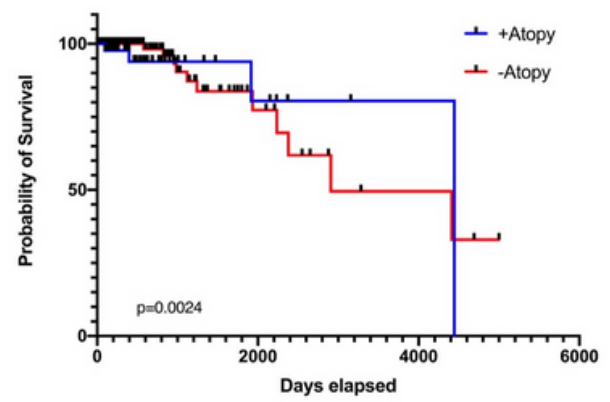

C

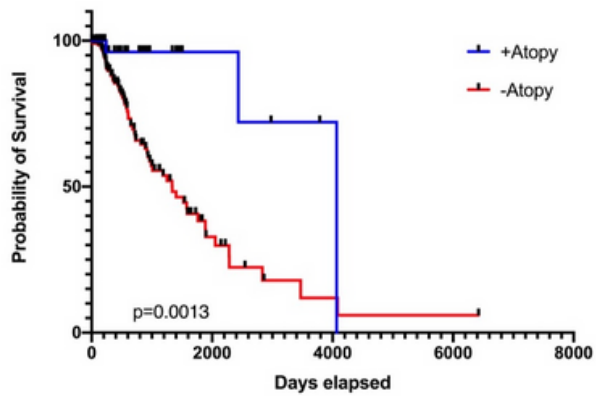

\section{Figure 3}

Kaplan Meier survival curves comparing histological grade in addition to atopy. A) Patients with WHO Grade II glioma experienced a statistically longer overall survival compared to those with WHO Grade III. B \& $\mathrm{C}$, a history of atopy confers a statistically significant increase in overall survival in both WHO Grade II and Grade III patients.

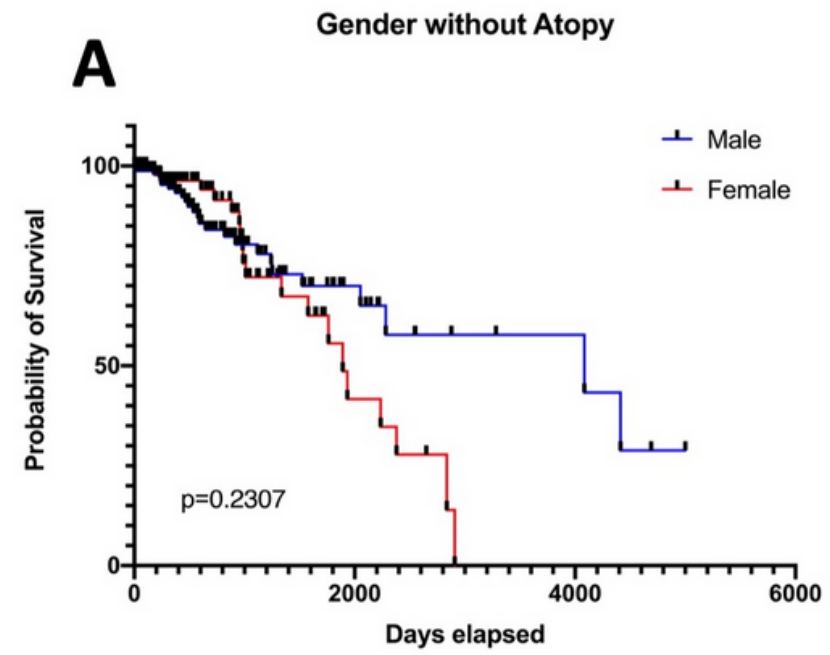

B

Gender with Atopy

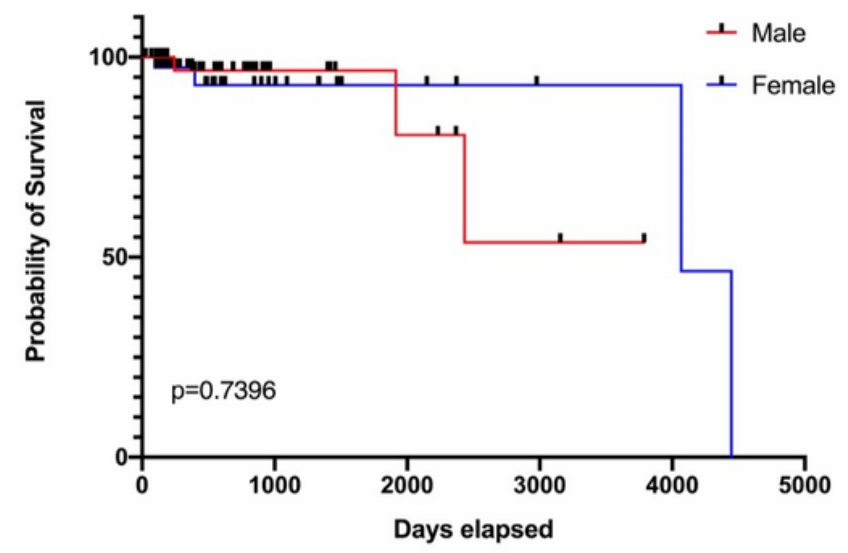

Figure 4

Kaplan Meier survival curves comparing gender and atopy. A) No statistically significant difference in survival outcomes between males and females without atopy. B) In patients with atopy, there is also no significant difference in outcomes between males and females. 

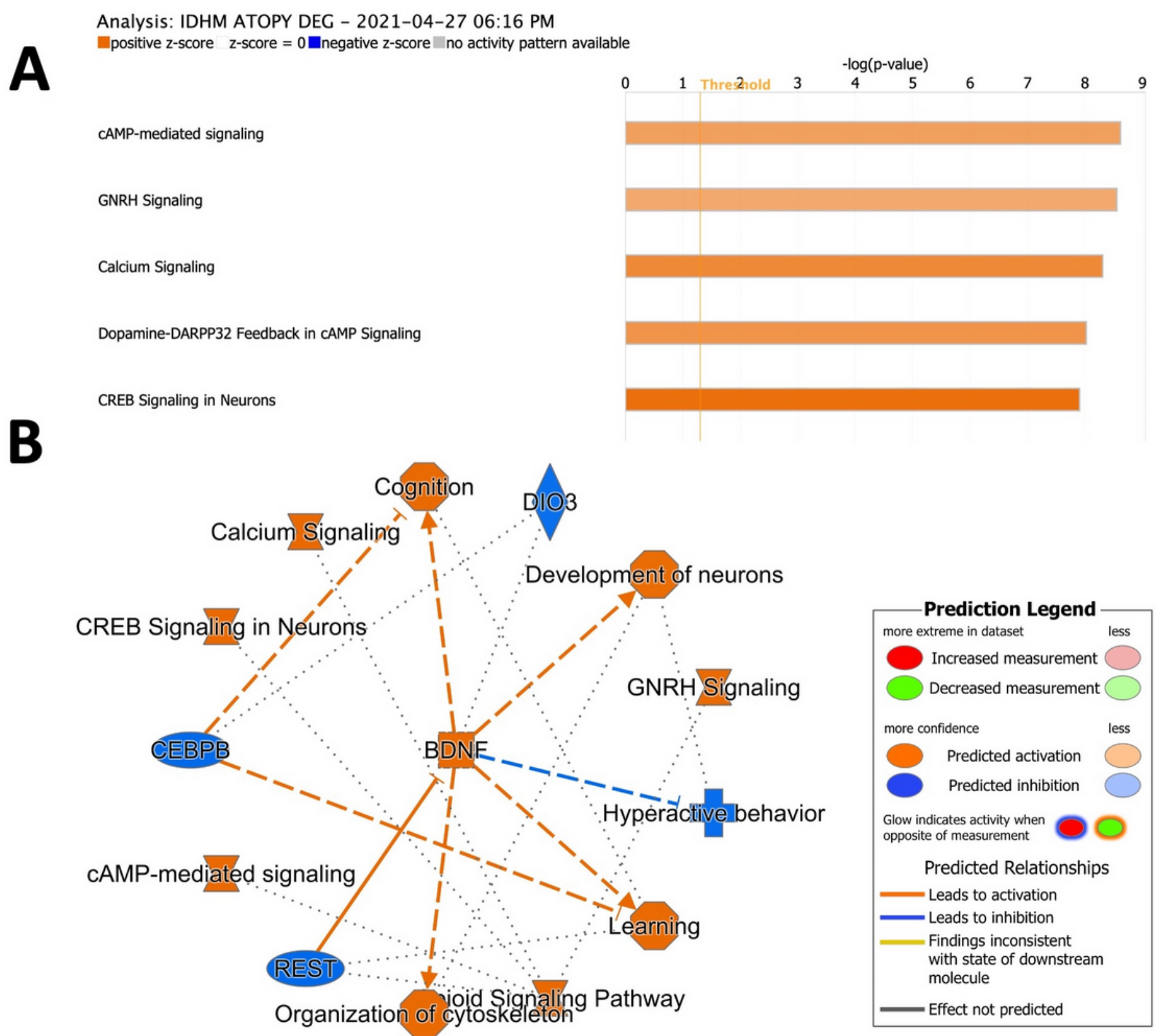

(ㄷ) 2000-2021 QIAGEN. All rights reserved.

\section{Figure 5}

Ingenuity Pathway Analysis results demonstrating A) top 5 most significantly altered canonical pathways and B) graphical summary of the most significant canonical pathways and upstream regulators, depicting the involvement and activation of the BDNF pathway. 